\title{
Exploring the Barriers and Enablers to the Use of Open Educational Resources by University Academics in Africa
}

\author{
Tanya Percy and Jean-Paul Van Belle \\ Department of Information Systems, University of Cape Town \\ Private Bag, 7701 Rondebosch, South Africa \\ TBPercy@gmail.com, Jean-Paul.VanBelle@uct.ac.za
}

\begin{abstract}
Considerable effort has gone into Open Educational Resource (OER) initiatives in the past decade. These initiatives have created free, high quality educational resources for everyone and anyone to use. However, these open and free resources appear to remain largely unused by university academics on the educationally resource-poor African continent. The objectives of the research study are to explore the inhibitors and enablers are experienced by academics that use OER, and what barriers prevent academics from using OER. The sample consists of academics from East, West and Southern Africa. Information was gathered by means of a survey questionnaire. A modified version of the Unified Theory of Acceptance and Use of Technology model was used to identify the influence of certain factors on a user's intention to adopt OER. Some of the key findings indicate that Performance Expectancy and Effort Expectancy have a positive effect on a user's Behavioural Intention to use OER, and the latter has a strong influence on the Actual Use of OER. Facilitating Conditions do not have a statistically significant impact. Additionally, significant differences were found in the barriers which users and potential users of OER have identified as either limiting their current use of OER, or negatively affecting their intention to use OER. These barriers include discovery, relevance, context and individual resources. Addressing these factors could lead to a more widespread adoption of Open Educational Resources in Africa and, consequently, more pervasive and higher quality educational opportunities.
\end{abstract}

\section{$1 \quad$ Introduction}

Education is seen as a basic human right which is central to the sustainable development of countries. However, this right is dependent on the relevant infrastructure being in place (Geith \& Vignare, 2008). This could include anything from content repositories to bandwidth to the removal of any barriers which prevent accessibility to educational resources.

The open education movement has been identified as a possible enabler of the educational shift from a teacher-centric model, where the educator is seen as the dispenser of knowledge, to a competency, learner-centred educational model (Geser, 2007). Making Open Educational Resources (OER) more accessible could reduce the 
social inequalities which exist in developing countries (Mora, Hassin, Pullin \& Muegge, 2008). It could provide a means of bypassing the educational barriers of economy, demographics and geography (Petrides, Nguyen, Jimes, \& Karaglani, 2008), correcting the imbalance which exists in the quality of education between developed and developing countries (Mora et al., 2008).

Considerable effort has gone into Open Educational Resource initiatives in the past decade. These initiatives have created free, high quality educational resources for everyone and anyone to use. However, even though these resources are open and free, it is not evident that these resources are being used by university academics on the relatively resource-poor African continent. This research study explores this question from an African academic's viewpoint. The objectives of the research study are to explore what barriers and enablers academics who use OER have experienced, and what barriers prevent academics from consuming OER.

\section{$2 \quad$ Literature Review}

\subsection{What Are Open Educational Resources (OER)?}

The term "Open Educational Resources" (OER) was first described at a UNESCO forum in 2002 as "the open provision of educational resources, enabled by information and communication technologies, for consultation, use and adaptation by a community of users for non-commercial purposes" (Friesen, 2009, p.1). Perhaps a more descriptive definition is: "digitized educational resources that are freely available for use by educators and learners, without an accompanying need to pay royalties or license fees. The digitized resources may be shared via the Internet or using media such as disk-drives. OER are usually, not exclusively, licensed using a Creative Commons license. Both the original owners of the material and the subsequent users need to clearly understand the terms of these contracts to appreciate the ways in which the materials may be remixed and shared." (West \& Victor, 2011, p.9). The latter definition highlights the key attributes of Open Educational Resources:

Educational resources should be in a digitized form. This indicates that educational resources should be made available on the internet or via another form of digitized media so that material is easier to distribute and reuse with the least cost. This is supported by the Organization for Economic Co-operation and Development (OECD), as their definition of OER is "digitised materials offered freely and openly to educators, students and self-learners to use and reuse for teaching, learning and research" (Mora et al., 2008 , p.1). Additionally, the tools which are used to support open educational initiatives must be open source in nature, where the source code is available for use (Geser, 2007).

Educational resources should be free and open to use. This allows users to collaborate, improve upon and share educational content and make the content more freely available and open to a global community (Petrides et al., 2008) under a licensing agreement, namely the creative commons license. 
Educational resources should be easily remixed and shared. OER content can be applicable to one user but not applicable to another (Koohang \& Harman, 2007). It is important that the content may be edited and versioned to the needs of the educator, learner or institution. West and Victor (2011) define Open Educational Resources as digitized educational material which can be edited and expanded for other uses. Figure 1 illustrates the range of resources that are typically included under OER.

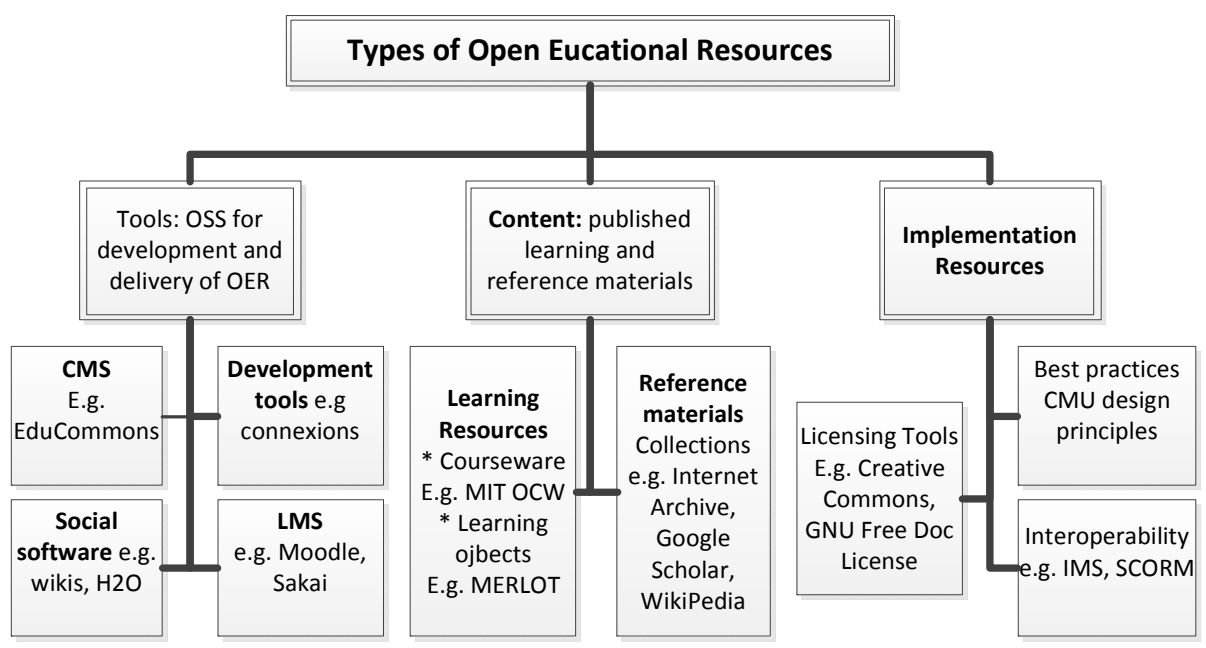

Fig. 1. Types of Open Educational Resources (Margulies, 2005)

\subsection{Benefits of Using OER}

Many advantages for using Open Educational Resources have been identified (D'Antoni, 2009). Educators have the option to download information as a supplement to the educators' coursework, and the ability to version and localize the content for their own use (Gourley \& Lane, 2009). Through the localizing of existing content, they can save time as copyright concerns would have already been resolved, and they do not need to produce content from scratch (Geser, 2007). Educators can be exposed to what colleagues are doing, and through observing others teaching practices, their own teaching can be improved (Hilton \& Wiley, 2010). Additionally, educators can provide their own comments on the educational material, by giving insight on how the content can be improved, and the lessons learnt through their sharing of the information (Geser, 2007).

It is through the use of Open Educational Resources that educators are encouraged to share materials and their ideas with other educators (Gourley \& Lane, 2009). Through this sharing of educational resources, which is core to academic values, educators encourage the development and support of new knowledge societies and, through such initiatives, the educators' reputation may be improved (D'Antoni, 2009). In a broader context, OER aims to make the best ideas available to those who want to use them and, additionally, empowers individuals to make use of alternative education avenues beyond those provided by the traditional education system (D'Antoni, 2009) e.g. e-learning and Open CourseWare $[\mathrm{OCW}]$ repositories. 


\subsection{Enablers and Barriers to the Use of OER}

The main enablers and barriers identified in the literature can be grouped under the following themes: technology; copyright; politics and culture; communities of practice; quality; and discovery, context and relevance.

\subsubsection{Technology}

As OER are digital by nature, they require that the basic Information and Communication Technology (ICT) infrastructure be in place in order to enable access to the localization and adoption of OER content. However, since basic ICT infrastructure often does not exist in developing countries (Stacey, 2007), technological barriers, such as the lack of access to modern computers and the internet, still prove to be barriers to the use of OER. Less than $10 \%$ of the population in South Africa has access to the internet; this figure is still lower in countries like Kenya, Nigeria and Tanzania (Wilson, 2008). Bandwidth is another issue (Stacey, 2007).

By making OER content available through web-based interfaces, technology has assisted in bypassing the barrier of interoperability and in making OER more accessible (Atkins et al., 2007). Their lack of skills in the technology inhibited educators from using the OER portal due to the amount of time it would take to learn the technology before content could be produced or edited (Petrides et al., 2008). Where users had experience in producing and editing content on the technology platform, the level of use and reuse was high. To achieve this, however, educators need to be trained in the creation, use and reuse of learning materials (Panke, 2011). Comment facilities on open content portals assisted users in producing or editing content (Petrides et al., 2008), as it was not completely new and daunting.

\subsubsection{Copyright}

Educators were concerned that copyright claims may be laid against them for the use or reuse of material where the author of the material had not granted the necessary permissions (Davis, et al., 2010). To counter these copyright concerns, a licensing system called the Creative Commons (CC) was established by Larry Lessig and others in 2001(Wiley \& Gurrell, 2009). The CC licensing framework allows individuals and organizations to publish their work (West \& Victor, 2011) under different types of Intellectual Property licenses (Kozinska et al., 2010). Additional flexibility of the framework allows authors to customize the license according to their requirements (Geith \& Vignare, 2008). Thus when potential users see the Creative Commons license, which changed the "all rights reserved" to "some rights reserved open licensing" (Gourley \& Lane, 2009, p.58), they know that the educational content is open and freely available for use (West \& Victor, 2011).

However, the use of Creative Commons licensing is subject to some debate, especially the "commercial" and "non-commercial" license options (Joyce, 2007; Bissell, 2009). Additionally, licensing can become a point of confusion where content is mixed from different sources. If one content source is registered under the noncommercial ShareAlike license and the other under the attribution ShareAlike license, a derivative of the original material cannot be used as the original licenses are incompatible (Wiley \& Gurrell, 2009). 


\subsubsection{Politics and Culture}

The right to education is currently more of an attainable goal in the developed, wealthier countries, whose aim is more on secondary education than it is in the poorer developing countries, whose aim is mainly primary education (Kozinska et al., 2010). Political, social and economic factors influence accessibility to information and communication technologies (ICT) (Mora et al., 2008).

Developing countries have additional barriers which exist, to a lesser extent, in developed countries. Of the open education content produced by developed countries, a large amount is in English and is based on Western Culture. This in itself could pose a large barrier to the adoption and use of open content in non-English speaking developing countries which may have fewer resources for translating materials (Mora et al., 2008). However, as the OER movement gains momentum and more organizations join the fray, the amount of OER content which has been translated has increased (Geith \& Vignare, 2008). Although potential cultural issues have also been mentioned (Mora et al., 2008), no actual supporting evidence has been provided for this barrier.

\subsubsection{Community of Practice}

The concept of "build it and they will come" (Hatakka, 2009, p.1) does not apply to open educational initiatives. In order for individuals to use Open Educational Resources, they have to feel part of the process and experience a sense of belonging (Windle, Wharrad, McCormick, Laverty, \& Taylor, 2010). This can be achieved through communities of practice.

There appears to be a correlation between the author group size and reuse of OER initiatives (Petrides et al., 2008). The size of an author group, and resultant collaboration between authors, increases the chance of reuse of OER initiatives (Petrides et al., 2008). These author groups can also be referred to as communities of practice.

Communities of practice can be seen as vehicles to improving the scalability of OER, as the members share a common interest or goal, in producing and sharing knowledge. The members have the freedom to join or leave the community, and to provide a mixed bag of different skills and experiences which, when combined, can create scalable OER (Koohang \& Harman, 2007).

A good example of a community of practice is the OpenCourseWare consortium which, by creating "a broad and deep body of open educational content using a shared model" (Friesen, 2009, p.10), provided institutions with the facility to apply the MIT model to their own courses. Wikipedia is another example where the Wikipedia community has assisted in improving the overall quality of content, through collaboration and redevelopment of content (Petrides et al., 2008). The Hewlett Foundation, a funding body for OER initiatives, is focusing on a community building model which will provide incentives to all the stakeholders, and will encourage a "culture of contribution" (Atkins et al., 2007, p.3). 


\subsubsection{Quality}

With the increase in the amount of OER content being shared, quality and quality assurance have been raised as major concerns (Kozinska et al., 2010). The term "quality" in itself is an issue, as quality can also be associated with the context within which it is used, and a sense of quality can only be gained once an individual forms a relationship with the material (Wiley \& Gurrell, 2009). Iiyoshi and Kumar (2008) support this by saying that, in order to be able to evaluate the quality of content, it needs to be understood by whom the information will be used, how it will be used and when it will be used. For example, if a resource is written in Spanish but used by an individual who speaks Chinese, then the content would not be seen as high-quality material for that individual.

OER is open and free, which makes it more easily available to individuals to use; however, the term "free" is often incorrectly associated with poor quality (Panke, 2011). The Open Source Software movement was originally seen in the same light. When the concept of "free software" originally arose, questions were raised about its quality (Wiley \& Gurrell, 2009). However, free and open software (FOSS) products have seen great successes, the openness associated with this software movement, has only increased the quality of the product.

\subsubsection{Discovery, Relevance and Context}

Finding resources on the World-Wide Web can be difficult due to the enormous amount of content available (Panke, 2011), and due to the lack of useful metadata. OER metadata is important in providing detail around the resource. For example, if an educator is searching for a video on a particular topic, but the video has to be viewed in order to decide its relevance, the educator would soon give up, as to review the entire video to determine its relevance would take too long (Wenk, 2010).

Contextual information is also important in order for the educator to decide resource relevance. For example, what was the feedback from learners who used this information, and was the quality of the content deemed to be of a high standard (Davis, et al., 2010)?

Some initiatives have been started to assist in overcoming these issues. For instance, the Commonwealth of Learning (COL) has provided a Google search called the Commonwealth of Learning's Knowledge Finder (Open Educational Resource, 2005) which can be used on any website to assist with the search for relevant OER material (Panke, 2011). This tool can be found at http://www.col.org/resources/ knowServices/Pages/kf.asp.

West and Victor (2011) identified that often the educational material is based on outdated educational design principles, and to update the material will burden the already overtaxed lecturers. When educators try to use the online learning content for their lectures, there may be issues if the content is not organized into smaller more manageable modules which can easily be mixed and combined to form learning content which matches that of the institution's course curriculum (Johnstone, 2005). 


\section{Research Methodology}

Currently there is very little research around the use of Open Educational Resources by the academic community specifically within an African context. Additionally, the focus of most OER research is still on the development and publication of OER repositories and on establishing policies around the creation and use of OER material (Andrade, 2011). By contrast, this research aims to identify the actual level of use of OER by academics in Africa, and to explain the factors which influence an academic's individual use of Open Educational Resources. The researchers adopted a positivist research philosophy.

\subsection{Research Model}

Through the critical literature review, the Unified Theory of Acceptance and Use of Technology (UTAUT) model was determined to be applicable to this research. The UTAUT model was developed through the analyses of elements across eight models (Venkatesh, Morris, Davis \& Davis, 2003). There are four core independent constructs or determinants of intention and use: Performance Expectancy, Effort Expectancy, Social Influence and Facilitating Conditions (Venkatesh et al., 2003). These four constructs have been used along with two additional constructs: Attitude toward Using Technology and Information Quality. Although these constructs have traditionally not had much influence on behavioural intention to adopt various types of information technologies (Venkatesh et al., 2003), the researchers thought it prudent to include them given the nature of the research question (quality was identified as an important attribute of educational resources) and the resource constraints faced by African academics (and students).

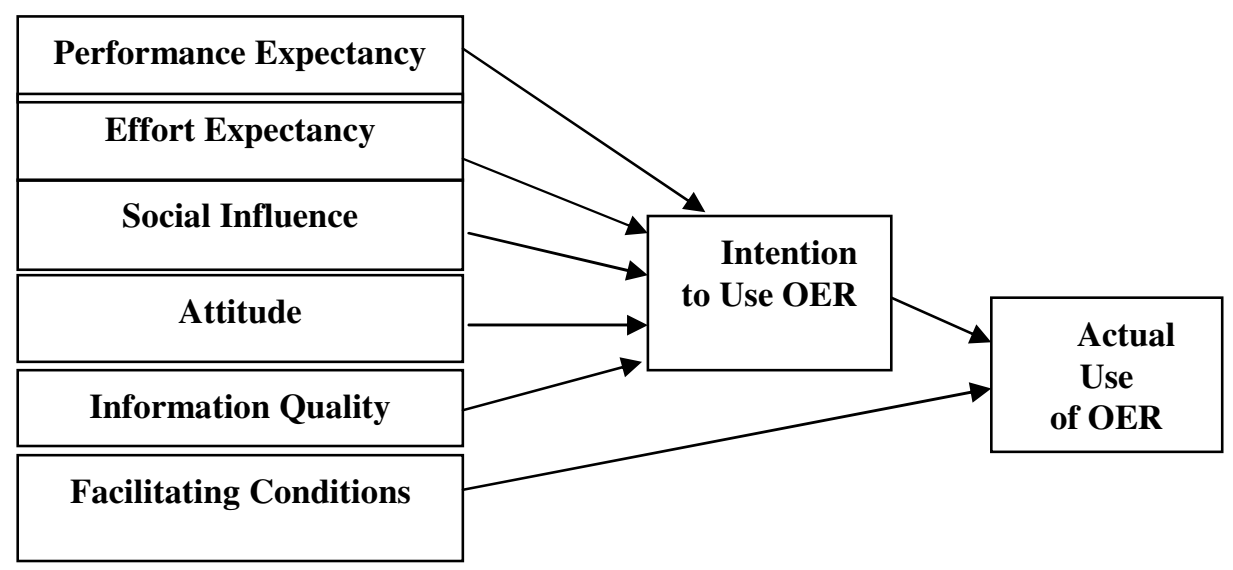

Fig. 2. Amended research model based on UTAUT with two additional constructs 
The independent variables are described in table 1 below.

Table 1. Explanation of the independent variables used in the research model

\begin{tabular}{|c|c|c|}
\hline Construct & Code & Description \\
\hline $\begin{array}{l}\text { Performance } \\
\text { Expectancy }\end{array}$ & $\mathrm{PE}$ & $\begin{array}{l}\text { How much the academic believes that OER will assist } \\
\text { them in performing better in their job. }\end{array}$ \\
\hline Effort Expectancy & $\mathrm{EE}$ & How easy it is to access and use OER. \\
\hline Social Influence & SI & $\begin{array}{l}\text { The extent to which academics are affected by people } \\
\text { within their circle of influence e.g. colleagues or friends. }\end{array}$ \\
\hline Facilitating Conditions & $\mathrm{FC}$ & $\begin{array}{l}\text { The extent to which an academic believes that there are } \\
\text { adequate resources i.e. technical infrastructure to support } \\
\text { their use of OER. }\end{array}$ \\
\hline $\begin{array}{l}\text { Attitude towards } \\
\text { technology }\end{array}$ & A & The overall reaction to using OER. \\
\hline Information Quality & Q & $\begin{array}{l}\text { The extent to which believes that the quality of the content } \\
\text { of the OER is sufficiently high for use in their courses. }\end{array}$ \\
\hline
\end{tabular}

\subsection{Research Design}

The target population includes academics in higher education institutions in Africa. The original population group was divided into the following strata: region, institution type and faculty. The regional strata were restricted to the English speaking regions of the African continent, namely South, East and West Africa. Within each of these regions higher educational institutions were identified and, to ensure that the barriers and enablers were adequately researched, the faculty strata covered both global and local content. The disciplines of Information Systems, Science and Mathematics were selected to ensure that the population group included areas where content can be used globally, as there is not much differentiation between local and global curricula. From a localized content perspective, the disciplines of Social Sciences and Humanities were incorporated into the research.

The actual sampling approach was convenience sampling, as it was identified that the responses would not be essentially or critically different across the different stratification dimensions, and there was "little variation in the population group" (Saunders et.al, 2009, p.41). The site used to gather information was the University Directory Worldwide (http://www.university-directory.eu/index.html) website, which provided a breakdown of universities by country. Some countries were omitted due to political tensions at the time of the survey or because insufficient academic contact data was publicly available.

Given the large geographic spread of the population of African academics, a survey was deemed to be the most appropriate data collection method. Apart from the demographic section, the questionnaire used the same items from previous surveys, as these were considered to be valid and reliable.

A total of 693 surveys were emailed to academics. 11 participants opted out of the survey, and 53 emails were undelivered. The total number of responses which could have been received was 629 . The total number of participants who started the survey was 96. Although most completed the demographic questions, only 68 respondents completed the entire questionnaire. Of those who responded but did not complete the survey, the following reasons were provided: "I [...] am absolutely flooded at the moment"; "it has been very hectic for me", "I had problem with internet access." 


\section{Data Analysis}

The quantitative data has been analysed using quantitative analysis techniques including graphs and statistics. The analysis has assisted in exploring the data, and has identified trends and relationships within the data.

\subsection{Sample Demographics}

Respondents were well spread between the English-speaking African regions West Africa (27\%), East Africa (28\%) and Southern Africa (41\%). There were also three respondents indicating that they were from North (2) or Central Africa (1).

Respondents were predominantly male with males accounting for $75 \%$ of the final data sample. However, this is representative of the target population of African academics since it corresponds quite closely with the original mailing list where the percentage of males varied from $87 \%$ (West Africa) to $72 \%$ (Southern Africa). Most respondents were in their thirties $(35 \%)$ or forties $(32 \%)$. Encouragingly, there were also quite a few young academic respondents (18\% in their twenties) but only 10 $(15 \%)$ of the academics older than 50. Almost one third (32.4\%) had 5 years or less of lecturing experience with a further $31 \%$ from 6-10 years. Only $15 \%$ had more than 20 years' experience.

There was also a good spread among faculties or disciplines: $29 \%$ were in information technology, $25 \%$ in the social sciences, $16 \%$ in science, $13 \%$ in the humanities, $12 \%$ in mathematics and only $4 \%$ from engineering. The majority of the respondents held the position of lecturer $(53 \%)$ or senior lecturer $(19 \%)$ while only $17 \%$ fell into a professorial category.

\subsection{Descriptive Analysis and Implications}

Firstly, the number of respondents which are users and non-users of OER was examined. The option in the questionnaire included a scale of use, from yes to some extent to a great extent. For the descriptive analysis, a breakdown of both the scale and the overall yes/no response will be analysed for completeness. Table 2 shows that the majority of the respondents are users of OER. However, this is unlikely to be representative of the larger academic population in Africa due to response bias: academics that are using OER can be assumed to be much more inclined to respond to the survey than the non-users.

Table 2. Use of OER by survey respondents

\begin{tabular}{|l|l|l|}
\hline & Frequency & Proportion \\
\hline No, not at all & 15 & $20.0 \%$ \\
\hline Yes, to a limited extent & 31 & $41.3 \%$ \\
\hline Yes, to some extent & 21 & $28.0 \%$ \\
\hline Yes, to a great extent & 8 & $10.7 \%$ \\
\hline Total & 75 & $100.0 \%$ \\
\hline
\end{tabular}


Also of interest is what type of Open Educational Resources the sample population is accessing the most. As identified in Figure 3, lecture notes and presentations are the most widely used OER.

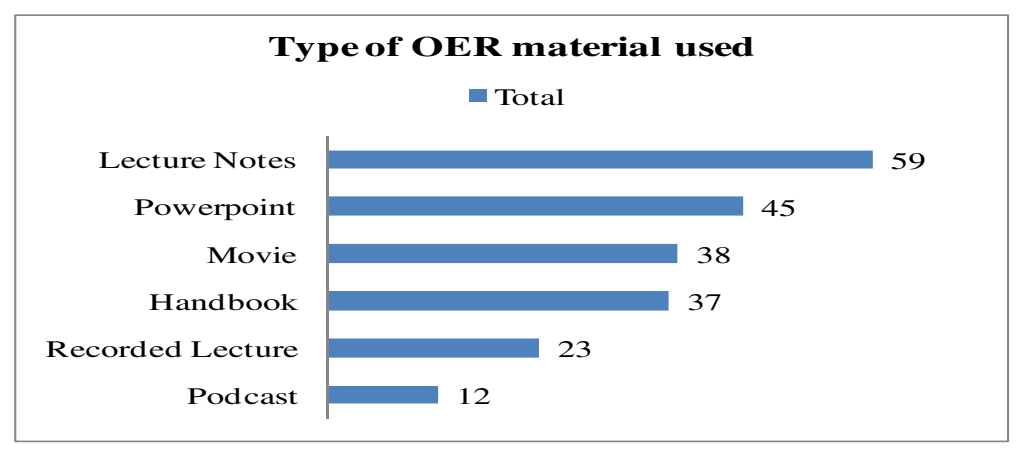

Fig. 3. Type of OER material used by respondents

\subsection{UTAUT Model}

This section tests the modified Unified Theory of Acceptance and Use of Technology (UTAUT) model regarding the factors which influence the Behavioural Intention to use (BI) and the actual Use Behaviour (UB) of Open Educational Resources.

\subsubsection{Validity and Reliability Tests}

The first step before performing any tests to support the UTAUT model is to ensure that the data used to support the model is both valid and reliable. In order to confirm this, a factor analysis and Cronbach Alpha test was performed on the data. The factor analysis is used to produce a matrix of the data, and assists in identifying correlations in the data which in turn are grouped into factors (Cairns, Oshlyansky \& Thimbleby (2007). This factor analysis has identified what questions have strong loadings to each other.

The initial factor analysis consisted of 6 factors, with a loading factor of .6 which is acceptable in the exploratory nature of this research study. However, the test items related to the constructs of attitude and information quality did not load clearly on distinct factors in the factor analysis tests and thus the model was reduced to the original UTAUT independent constructs, namely Performance Expectancy (PE), Effort Expectancy (EE), Social Influence (SI) and Facilitating Conditions (FC). Table 3 shows the factor loadings for the final model. Not all test items loaded fully on the remaining constructs and those were also removed for further analysis.

Since multiple item constructs were used, it is important to test the reliability of the constructs (Hong, Im \& Kang, 2010). The common test for this is the Cronbach alpha test. The Cronbach's Alpha coefficients were high, ranging from 0.766 (UB) to 0.894 (EE), except for the Facilitating Conditions (FC) construct which had a Cronbach $\alpha$ score of .678. However, this was considered acceptable given the small sample size. 
Table 3. Factor loadings for final test items on the four factors

\begin{tabular}{|c|c|c|c|c|}
\hline \multirow[b]{2}{*}{ Variable } & \multicolumn{4}{|c|}{$\begin{array}{l}\text { Factor Loadings (Varimax normalized) (2_stats_da } \\
\text { Extraction: Principal components } \\
\text { (Marked loadings are }>.600000 \text { ) }\end{array}$} \\
\hline & $\begin{array}{c}\text { Factor } \\
1\end{array}$ & $\begin{array}{c}\text { Factor } \\
2\end{array}$ & $\begin{array}{c}\text { Factor } \\
3\end{array}$ & $\begin{array}{c}\text { Factor } \\
4\end{array}$ \\
\hline Q11-AddValueWork & 0.653724 & 0.252669 & 0.145020 & 0.386150 \\
\hline Q12-SupplementInfo & 0.748003 & 0.105167 & -0.158091 & -0.197293 \\
\hline Q13-EnhanceTeaching & 0.813590 & 0.003901 & 0.088276 & -0.069086 \\
\hline Q14-StudentBenefit & 0.689388 & -0.123261 & 0.061129 & 0.164467 \\
\hline anceEffective & 967 & -0.136840 & 946 & 9629 \\
\hline Q16-EasierToDoJob & & & & 0278 \\
\hline Q19-IncreaseQualityT & 0.766278 & -0.267031 & 0.037528 & 0.191982 \\
\hline Q20- & 0.67 & -0.0 & & 0.301214 \\
\hline Q41-OERGoodldea & 0.688746 & 0.281148 & -0.202692 & 0.117587 \\
\hline cturelnteresting & & & & 0.309113 \\
\hline Q22- & & 01 & -0.1 & 0.763372 \\
\hline Q23-EditMixMaterial & 0.280280 & 0.262609 & -0.097467 & 0.822505 \\
\hline Q40-FearCriticism & 0532 & -0.082305 & 0.906259 & -0.079742 \\
\hline Q47-FearQuestions & -0.057728 & 0.517517 & -0.549841 & -0.333532 \\
\hline Q39-PeopleF & & 0.229541 & & -0.192585 \\
\hline Q33-HaveRes & -0.043127 & 0.782036 & -0.099084 & 0.009957 \\
\hline Q34-QuickEasyDownl & & & 0.098947 & 0.305174 \\
\hline Q35-KnowledgeToF & -0.124497 & 0.750801 & 0.097745 & 0.315708 \\
\hline Expl.Var & 5.602239 & 2.3 & 2.177901 & 2.143630 \\
\hline Prp.Totl & 0.311236 & 0.130915 & 0.120995 & 0.11909 \\
\hline
\end{tabular}

\subsubsection{Data Analysis and Implications}

The UTAUT model is used to analyze the direct determinants of a user's intention to use a technology and their usage behaviour (Venkatesh, Morris, Davis \& Davis, 2003).

To support the UTAUT model, the independent variables of Performance Expectancy (PE), Effort Expectancy (EE) and Social Influence (SI) were analysed to identify if they had a positive or negative effect on the dependent variable Behavioural Intention (BI). Additionally, the independent variable Facilitating Conditions (FC) was analysed to identify if there was a positive or negative correlation between FC and Usage Behaviour (UB).

The most important relationships of the UTAUT model are those relationships between the independent constructs of PE and EE, to the use intention (Hong, Im \& Kang, 2010). It needs to be noted that the scores for each construct were weighted prior to any data analysis.

Performance Expectancy was used to determine how much an individual believed that a certain technology would assist them in performing better in their job. $87.9 \%$ of the responses to the questions concerning Performance Expectancy gave a rating of agree somewhat to strongly agree. This implies that OER adds both value and quality to academics' teaching, thereby improving their overall job performance. The correlation between PE and BI was statistically significant $(\mathrm{p}<0.05)$.

The questions for the EE construct are focused on what the population perceived as the expected effort required in using OER. If the effort required in adopting a technology is high, then the chances of those individuals adopting the relevant technology will be low, and vice versa. $55 \%$ of the participants agreed that OER is 
easy to format and mix, $24 \%$ were undecided and, of the remainder, $10.59 \%$ disagree. Even though the majority agreed that they expected there wouldl be little expected effort required to adopt OER, large portions of the population were undecided or disagreed with the questions. Detailed analysis indicates that it is the non-users who were undecided about the amount of effort required to use OER, as $46 \%$ of them selected the undecided option. This could be indicative of their lack of experience and or exposure to OER, and to their resultant uncertainty about how much effort would be required to adopt OER. There is a statistically significant correlation between EE and $\mathrm{BI}(\mathrm{p}<0.05)$.

The Social Influence construct focused on the influence which other individuals had on the participant's intention to use OER. The two questions which make up this construct are on faculty members' influence and on the fear of criticism from others if the participant used OER. The majority of the participants disagreed with these questions, indicating that academics are not influenced to any great extent by others. Additionally, the Pearson correlation coefficient between SI and BI is too low to be significantly significant. Out of the four constructs of PE, EE, SI and FC, SI has the least impact on an individual's intention to use OER.

The facilitating conditions construct identifies whether participants have access to resources or have the knowledge to use or find OER. As per the UTAUT model, it is identified that facilitation conditions influence the Use Behaviour of an individual but not the individual's intention to use OER. However, in this research study, Facilitating Conditions were positively and statistically significantly correlated to both an individual's Behavioural Intention and their Use Behaviour towards OER.

The Behavioural Intention construct focuses on the user's intention to use OER, and is a dependent construct in our model. The responses for these test items (Table 4) confirm the "use" responses shown earlier (Table 2).

Table 4. Behavioural intention to use OER

\begin{tabular}{|l|c|c|c|c|c|c|c|}
\hline & $\begin{array}{c}\text { Agree } \\
\text { strong } \\
- \text {-ly }\end{array}$ & Agree & $\begin{array}{c}\text { Agree } \\
\text { some- } \\
\text { what }\end{array}$ & $\begin{array}{c}\text { Un- } \\
\text { decided }\end{array}$ & $\begin{array}{c}\text { Disagree } \\
\text { some- } \\
\text { what }\end{array}$ & $\begin{array}{c}\text { Dis- } \\
\text { agree }\end{array}$ & $\begin{array}{c}\text { Dis-agree } \\
\text { strongly }\end{array}$ \\
\hline OER fits the way I work & $10 \%$ & $35 \%$ & $29 \%$ & $18 \%$ & $3 \%$ & $1 \%$ & $3 \%$ \\
\hline Will use OER in future & $21 \%$ & $44 \%$ & $24 \%$ & $10 \%$ & $1 \%$ & $0 \%$ & $0 \%$ \\
\hline Will use OER in next 2 years & $10 \%$ & $41 \%$ & $24 \%$ & $15 \%$ & $3 \%$ & $3 \%$ & $4 \%$ \\
\hline Would join OER community & $7 \%$ & $32 \%$ & $25 \%$ & $21 \%$ & $1 \%$ & $9 \%$ & $4 \%$ \\
\hline
\end{tabular}

Use behaviour was measured by 7 test items. A statistically significant and positive correlation exists between Behavioural Intention (BI) and Use Behaviour (UB). A multiple regression test was done in order to estimate the strength of relationships between the dependent and independent constructs.

The multiple regression analysis (Table5) for the dependent variable BI shows an overall $\mathrm{R}^{2}$ score of 0.53 . This indicates that $53 \%$ of the variance in the Behavioural Intention to adopt OER is explained by the three constructs Performance Expectancy, Social Influence and Effort Expectancy. However, SI is not a significant predictor $(\mathrm{p}=0.171)$ when the other two significant variables are taken into account. 
Table 5. Multiple regression summary for Behavioural Intention to Use OER

\begin{tabular}{|l|l|l|l|l|l|l|}
\hline & $\mathrm{b}^{*}$ & Std.Err. & $\mathrm{b}$ & Std.Err. & $\mathrm{t}(64)$ & $\mathrm{p}$-value \\
\hline Intercept & & & 0.0980 & 0.1138 & 0.8604 & 0.3928 \\
\hline Performance Expectancy (PE) & 0.5060 & 0.1015 & 1.2302 & 0.2468 & 4.9853 & $0.0000^{*}$ \\
\hline Social Influence (SI) & 0.1249 & 0.0903 & 0.0475 & 0.0343 & 1.3836 & 0.1713 \\
\hline Effort Expectancy (EE) & 0.3018 & 0.0989 & 0.1215 & 0.0398 & 3.0527 & $0.0033^{*}$ \\
\hline $\mathrm{R}^{2}=0.5280 ;$ Adjusted $\mathrm{R}^{2}=0.5059 ; \mathrm{F}(3,64)=23.866 ;$ & $\mathrm{p}<0.00000 ;$ & Std.Err of estimate: 0.1778 \\
\hline
\end{tabular}

Table 6. Multiple regression summary for Use Behaviour of OER

\begin{tabular}{|l|l|l|l|l|l|l|}
\hline & $\mathrm{b}^{*}$ & Std.Err. & $\mathrm{b}$ & Std.Err. & $\mathrm{t}(64)$ & $\mathrm{p}$-value \\
\hline Intercept & & & 0.1360 & 0.0415 & 3.2763 & $0.0047 *$ \\
\hline Behavioural Intention $(\mathrm{BI})$ & 0.7315 & 0.0959 & 0.3659 & 0.0480 & 7.6300 & $0.0000^{*}$ \\
\hline Facilitating Conditions & -0.0400 & 0.0959 & -0.0146 & 0.0350 & -0.1475 & 0.6777 \\
\hline $\mathrm{R}^{2}=0.7153 ;$ Adjusted $\mathrm{R}^{2}=0.5117 ; \mathrm{F}(2,65)=34.052 ; \mathrm{p}<0.00000 ;$ & Std.Err of estimate: 0.0897 \\
\hline
\end{tabular}

For the dependent variable $\mathrm{UB}$, the overall $\mathrm{R}^{2}$ score was 0.51 (Table 6). This indicates that $51 \%$ of the variance in UB can be explained. However, the direct impact of Facilitating Conditions is not statistically significant when BI's contribution is taken into account. Figure 4 shows the overall correlations between the independent and dependent constructs using the Beta coefficients from the multiple regression tests.

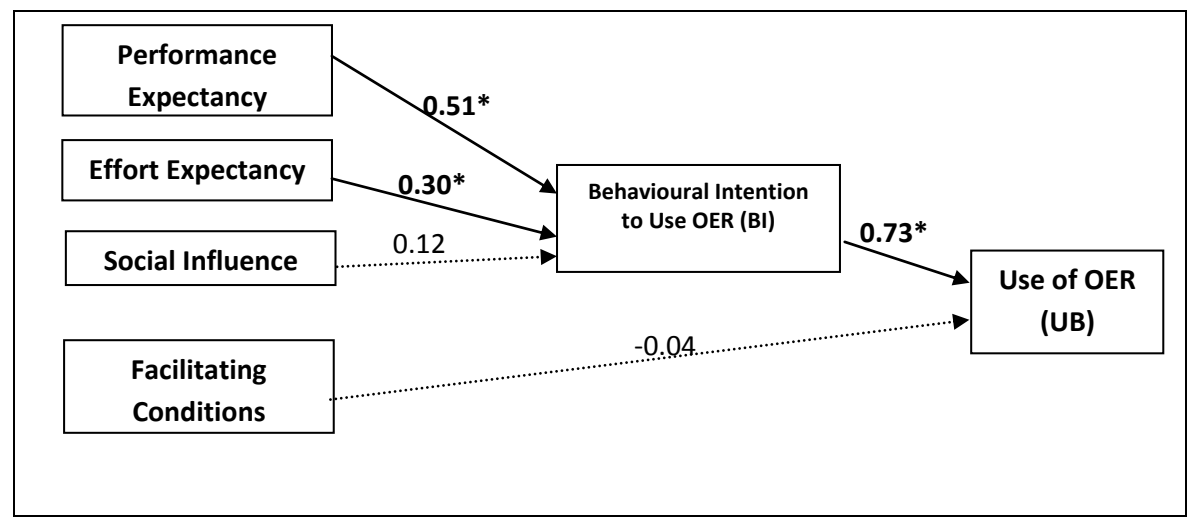

Fig. 4. Correlations between model constructs $(*=$ significant at $\mathrm{p}<0.05)$

\subsection{Perceived Barriers to the Adoption of OER}

In a manner, this reduces the final validated model back to the original parsimonious Technology Acceptance Model, where Performance Expectancy can be seen to represent Perceived Usefulness, and Effort Expectancy as a proxy for Ease of Use.

The second objective of this research was to analyze the perceived barriers to the use of OER. Respondents were requested to select multiple options which they 
perceived to be barriers to using Open Educational Resources. The resultant selected barriers from the survey questionnaire were grouped into the six main themes identified earlier in the literature review. Where the data did not fit into the predetermined groupings, a new barrier grouping was created.

The cumulative score per barrier grouping was calculated to identify the highest perceived barriers to the use of OER by academics (figure 5).

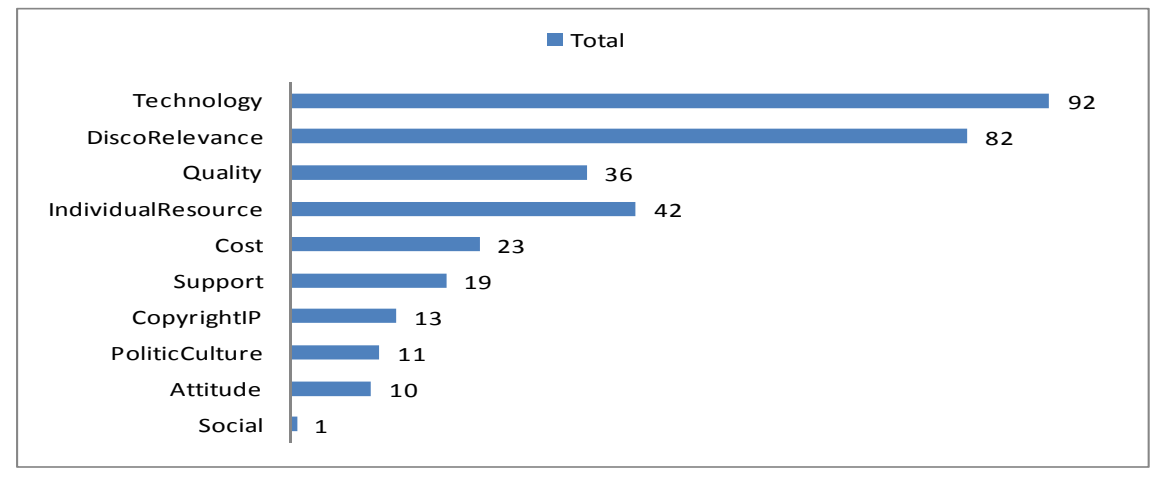

Fig. 5. Perceived barriers to the adoption of OER

The two most crucial barriers appear to be the technological barrier - as previously identified by Stacey (2007) - and the difficulties experienced in discovering OER and assessing their relevance and context. Also important are the lack of individual resources (time and personal skills) and the perceived quality of OER.

The barriers were also compared between users and non-users of OER, to identify whether the overall barriers experienced by users and non-users are the same. A Chisquare analysis confirmed that there were statistically significant differences between the two groups of academics $(p=0.0028)$. The main contributor to the significant difference was the lack of individual resources (which was rated as the most critical barrier for the non-users), although users rated the difficulty in discovering and assessing their relevance/context also significantly higher than the non-users.

Note that, although the political and cultural barrier was not identified as being significant in this research, there were perhaps insufficient questions around what political or cultural barriers the academic population could experience within an African context. Future research should look at this barrier on its own within the academic OER context, in order to identify whether the political and cultural barriers effect the adoption of OER within Africa as compared to developed countries. Additionally, local legal and organisational circumstances may have constrained academics from adopting OER, e.g. where they cannot change the curriculum.

\section{Conclusion}

The research has identified that academics' attitudes towards OER is positive as the majority of the respondents agree that OER can add value to their work as an 
academic. Interestingly, only two of the UTAUT model influencing variables were found to exert significant influence on the academics' intention to adopt OER: the Performance Expectancy i.e. the degree to which OER are expected to add value to their work, and Effort Expectancy, the amount of work they expect to have to do to obtain and use OER. In effect, these findings reduce the model to the original, more parsimonious Technology Acceptance Model which was the foundation of the UTAUT model, where (Perceived) Usability and Usefulness were hypothesized to be the key drivers of Behavioural Intention. However, these two variables explained more than half of the variance in Behavioural Intention to Use OERs, and the latter also explained over half the variance in OER Use Behaviour.

Another aim of this research study was to identify the main barriers to the use of Open Educational Resources by academics within Africa. The main barriers identified are those of technology, discovery, relevance, quality and individual resources.

The key barrier experienced by the respondents is that of technology i.e. lack of access to computers, lack of internet access and/or poor bandwidth. Although these issues have been identified in prior research, the confirmation of these findings adds more urgency to the need to find solutions to the poor technological infrastructure which exists in developing countries.

A more unexpected finding is that OER users rated the difficulty of both discovering what Open Educational Resources are available to use and determining their relevance to their environmental context or subject area as equally critical barriers. Interestingly, the expected barrier of Western context or bias, considering most of the published OER material originates from developed countries, was not seen as a significant barrier.

\subsection{Recommendations}

One of the questions in the survey questionnaire was for academics to comment on what would encourage them to use OER. Some of the underlying themes were communication, advertising, training and awareness.

The recommendation to the OER community is to market and advertise OER to the African academic community. It will improve academics' awareness of what is available and what benefits can be gained through using OER. This may address the key barrier of discovery, relevance and context, since, even though there have been improvements in the search facilities and repositories of OER content, these changes have not been communicated effectively to the greater African academic community.

From a skills perspective, academics believe that gaining access to and using OER is complicated, and that individuals need to be trained in the necessary skills required to use OER. Although this point does have some merit for individuals without a basic level of computer literacy, there needs to be better communication around which OER repositories exist and the ease with which Open Educational Resources can be accessed.

\section{$5.2 \quad$ Future Research}

The sample was fairly small and there is a strong suspected response bias towards respondents that are familiar with and have used OER. A larger scale and more 
systematic survey would be more representative of the African academic community. In particular, future research should attempt to include academics from the Arabic and French-language North and West African regions. OER research in other developing countries could compare both the model fit and barriers and possibly highlight those factors that are more uniquely African.

Future research could also examine the barriers to OER adoption in more detail. A larger sample is likely to reveal additional significant influencing factors beyond Effort and Performance Expectancy.

In particular, the barriers of culture and politics were not investigated to a great enough extent in this research. In order to determine whether politics and culture (or other factors) have a significant impact on an individual's adoption and use of OER, a qualitative study could be completed for academics within Africa, in order for the underlying feelings and attitudes towards culture and politics to be understood.

\section{References}

Andrade, A., Ehlers, U., Caine, A., Carneiro, R., Conole, G., Kairamo, A., et al.: Beyond OER: Shifting Focus to Open Educational Practices. Open Education Quality Initiative (2011)

Atkins, D.E., Brown, J.S., Hammond, A.L.: Resources (OER) Movement: Achievements, Challenges, and New Opportunities (2007)

Bissell, A.N.: Permission granted: open licensing for educational resources. Open Learning 24(1), 97-106 (2009)

Carson, S.: The unwalled garden: Growth of the OpenCourseWare consortium, 2001-2008. Open Learning 24(1), 23-29 (2009)

D'Antoni, S.: Open Educational Resources: reviewing initiatives and issues. Open Learning 24(1), 3-10 (2009)

Davis, H.C., Carr, L., Hey, J.M., Howard, Y., Millard, D., Morris, D., et al.: Bootstrapping a Culture of Sharing to Facilitate Open Educational Resources. IEEE Transactions on Learning Technologies 3(2), 96-108 (2010)

De Liddo, A.: From open content to open thinking. In: World Conference on Educational Multimedia, Hypermedia and Telecommunications (Ed-Media 2010), Toronto, Canada (2010)

Downes, S.: Models for Sustainable Open Educational Resources. Interdisciplinary Journal of Knowledge and Learning Objects 3, 29-44 (2007)

Dulle, F.W., Minishi-Majanja, M.: The suitability of the UTAUT model in open access adoption studies. Information Development 27(1), 32-45 (2011)

Friesen, N.: Open Educational Resources: New Possibilities for Change and Sustainability. International Review of Research in Open and Distance Learning 10(5), 1-13 (2009)

García-Peñalvo, F.J., Figuerola, C.G., Merlo, J.A.: Open knowledge: challenges and facts. Online Information Review 34(4), 520-539 (2010)

Geith, C., Vignare, K.: Access to education with online learning and open educational resources: Can they close the gap? Journal of Asynchronous Learning Networks 12(1), 1-22 (2008)

Geser, G.: Open Educational Practices and Resources. EduMedia Group, Salzburg (2012)

Gourley, B., Lane, A.: Re-invigorating openness at The Open University: the role of Open Educational Resources. Open Learning: The Journal of Open, Distance and eLearning 24(1), 57-65 (2009) 
Hatakka, M.: Build it and they will come? Inhibiting factors for reuse of open content in developing countries. The Electronic Journal on Information Systems in Developing Countries 37(5), 1-16 (2009)

Hilton, J., Wiley, D.A.: The Creation and Use of Open Educational Resources in Christian Higher Education. Christian Higher Education 9(1), 49-59 (2010)

Hýlen, J.: Giving Knowledge for Free: The Emergence of Open Educational Resources. OECD-CERI, Paris (2007)

Johnstone, S.: Open Educational Resources Serve the World. Educause Quarterly 3, 15-18 (2005)

Kanwar, A., Kodhandaramana, B., Umar, A.: Toward Sustainable Open Education Resources: A Perspective From the Global South. American Journal of Distance Education 24(2), 65$80(2010)$

Koohang, A., Harman, K.: Advancing Sustainability of Open Educational Resources. Issues in Informing Science and Information Technology 4, 535-543 (2007)

Kozinska, K., Kursun, E., Wilson, T., McAndrew, P., Scanlon, E., Jones, A.: Are open educational resources the future of e-learning? In: 3rd International Future-Learning Conference: Innovations in Learning for the Future. The Open University, Instanbul (2010)

Mora, M., Hassin, K., Pullin, A., Muegge, S.: Open Educational resources and the evolving value chain of education in developing countries. In: IEEE International Symposium on Technology and Society, June 26-28, pp. 1-10 (2008)

Panke, S.: An Expert Survey on the Barriers and Enablers of Open Educational Practices (2011), http: / / elearningeuropa.info

West, P.G., Victor, L.: Background and action paper on OER (2011), http://www. paulwest.org/public/Background_and_action_paper_on_OER.pdf 